\title{
Accounting Practices and Organizational Performance: Evidence from Small and Medium Scale Enterprises in Sri Lanka
}

\author{
Saseela Balagobei \\ Senior Lecturer \\ Department of Financial Management \\ University of Jaffna \\ Sri Lanka \\ E-mail: saseelab@univ.jfn.ac.lk
}

\begin{abstract}
Over the past few decades, the researchers demonstrate consistent effort in investigating the Small and Medium scale Enterprises (SMEs). This sector plays a crucial role in the economic growth in both developing and developed countries. The research investigated how accounting practices influence the organizational performance of small and medium scale enterprises in Sri Lanka. Accounting practices consists of record keeping, budgeting practices and payroll accounting whereas organizational performance is measured by organizational goal achievement, organizational effectiveness and organizational efficiency records. A structured questionnaire was used to collect the primary data from 75 SMEs which were selected by means of the random sampling technique. The results revealed that among the accounting practices, only record keeping and budgeting practices have significant positive influence on organizational performance of Small and medium enterprises in Sri Lanka. It can be recommended that academic institutions and other bodies which are responsible for SMEs should organize training programmes for those operators who do not have the technical knowhow in the field of accounting to come to grips with it and also provide some SME-specific accounting guidelines and template forms for capturing accounting practices for the operators to use.
\end{abstract}

Keywords: Accounting Practices, Organizational Performance, Record Keeping, Budgeting Practices.

JEL Classification: M4I.

\section{Introduction}

Small and medium enterprises (SMEs) are considered as vital for promoting economic growth and social development of Sri Lanka. In recent years, SMEs have been identified as a key source of income generation, employment, poverty alleviation and regional development. The SMEs engage in broad areas of economic activity such as agriculture, mining, manufacturing, construction and service sector industries. Accounting practices are crucial in the success of contemporary business organizations. It foils the exploitation of assets, increases production and yield, controls expenses and helps to improve the efficiency of the overall management. The role of management is vital in the whole development of a business organization. Accounting is an essential tool for recording, analyzing, monitoring and evaluating the financial status of the organisations. It provides a source of information to owners and managers of SMEs operating in any industry for measuring financial performance (Maseko \& Manyani, 20II).

Today's accounting system provides more appropriate, consistent and suitable financial information to stakeholders to make the effective financial decisions concerning their business entities. According to the business dictionary 'Accounting' can be defined as a systematic procedure that helps to identify record, measure, classify, verify, summarize, interpret, and communicate financial information. It reveals profit or loss for a specific period, and the value and nature of an organization's assets and liabilities and owner's equity. It involves ascertainment, recording, summarizing, and reporting of financial facts used in evaluating and monitoring an organization's economic undertakings. An accounting system, therefore, is an organized discipline of manual and computerized accounting methodology, processes, and wheels which are employed in gathering, recording, classifying, analyzing, summarizing, interpreting, and presenting accurate and timely financial information for decision making in an organization.

The importance of organizational performance measurement to any business organization, large or small, can't be over-emphasized. In any sense, profit can analogously be viewed as the life-blood of a business and hence the accounting bases, concepts and principles adopted ought to capture and report all the relevant accounting information to ensure reliability in its measurement. Reported profits reflect changes in wealth of owners and this can explain why major economic decisions in business are centered on financial performance as measured by profitability (Cooley \& Edwards, I983). It has 
been recognized that appropriate accounting information is important for a successful management of any business entity, whether large or small (European Commission, 2008).

It is fundamental therefore that accounting practices of SMEs supply potential and appropriate financial information needed to economic decisions made by entrepreneurs. The study therefore mainly focuses on investigating the types of accounting practices followed by SMEs, their completeness and the availability of accounting skills and knowledge to capture and process accounting information which can be used to measure performance in SMEs. The accounting practices such as the cost accounting practices, the financial accounting practices and even the management accounting practices provide more information on the performance and other useful material about the organization to the stakeholders. The purpose of financial statements is to provide information about the financial position, financial status, performance and changes in financial position of an organization that is valuable to various users in making effective decisions.

Similarly, accounting practices are the procedures and controls that accounting departments use for creating and recording business transactions. Accounting practice should ideally be tremendously constant, since many business transactions must be dealt with in exactly the same way in order to prepare consistently reliable financial statements.

SME development is vital for any country, since this sector has great prospective to create maximum social and economic advantages to the country with minimum investment. SMEs make up 80 per cent of all businesses, approximately 20 percent of industrial establishments. The SMEs accounts for more than ninety percent of business establishments and are estimated to contribute about thirty five percent of employment in the service sector. The SMEs play an important role in developing the country.

There are few studies conducted on accounting practices and organizational performance of SMEs in Sri Lanka. These studies conducted have not shown that how all components in accounting practices improve the overall organizational performance of SMEs in Sri Lanka. Therefore the study attempts to examine the effect of accounting practices on organizational performance of SMEs in Sri Lanka

\section{Research Problem}

One of the the problems of SMEs failure is poor management including accounting problem-solving. SMEs face difficulties in increasing equity capital from the individuals and financial institutions. Even when the financial institutions approve to obtain equity capital, the conditions are always dreadfully frightened. Therefore there is inadequate capital available to SME and thus lead to poor funding facilities.

Further the issues experiencing SMEs is dearth of proficient management which affects the ability of entrepreneurs to employ the services of experts; usage of obsolete equipment and devices of production because of entrepreneur's inability to access new technology; more competition which resulted from sales which is a consequence of poor finance to cope with increased competition in the industry; The highest cost of available raw materials influences the prices of finished goods. It only has adverse consequence on the business of the enterprise but also on the success; the availability of infrastructural facilities is totally inadequate in the areas of access roads, electricity, water supply, etc. and various policies and regulatory measurements such as exclusion of fuel subsidy, taxes, and burdens on loans.

Although the role of SMEs in the country is significant, they face challenges and problems. In Sri Lanka there are more failures of SMEs and the Central Bank of Sri Lanka (1998) indicated that insufficient capital and loan facilities, improper accounting techniques and etc. The failure of SMEs to find their counter funds obligations as a condition of financial arrangements generates another obstacle for SMEs to acquire the facilities offered in concessionary finances (Abeygunasekera \& Fonseka 2012). However, inefficient record keeping practices, incompetent use of accounting information to support the financial decision making and the low quality and consistency of financial facts are main problems in financial management concerns of SMEs (Karunananda \& Jayamaha, 20II).

The place of sound accounting and internal control systems of any enterprises, regardless of its scale, cannot be overstated. A vast majority of SMEs cannot afford the complication of a detailed accounting system even if they would have. Hence, the existence of single entry in books and in some cases incomplete records (Onaolapo, et al., 20II). Audits of SMEs have proven to be among the most worrisome for professional accountants as the internal controls are inadequacy. But for statutory demands, SMEs hardly provide critical thoughts to the process of sound accounting, yet the insufficiency and incompetence of accounting processes have been answerable for untimely failure of a host of them (Aremu \& Adeyemi, 20II). Based on the problem, the following research question is formulated, to what extent accounting practices influence the organizational performance in Sri Lanka?

\section{Objectives of the Study}

Accounting information is fruitful in important activities as: the evaluation of position of enterprises in terms liquidity, profitability, leverage and activities; measurement of performance; and assessment of the effectiveness of alternative courses of action. The objective is to investigate the impact of accounting practices on organizational performance of SMEs in Sri Lanka. 


\section{Literature Review}

There have been some studies that link between accounting practices and organizational performance of enterprises. For instance, Onaolapo \& Adegbite (20I4) investigate the impact of accounting records on SMEs' business performance. The primary data were gathered by using interviews and questionnaires from sample of II3 SMEs using a mixture of stratified and purposive sampling techniques. Descriptive statistics, Chi-square and ANOVA were employed for analyzing the data. The results revealed that accounting records keeping has a strong positive relationship with SMEs' performance.

Yousef (2013) conducts a study on the use of accounting information by SMEs in the south district of Jordan. Data were systematically gathered using a list of questions from a sample of I36 SMEs. The study shows that the level of awareness on the significance of financial management and accounting information is still very low among SMEs in the south district of Jordan.

Amaoko (2013) studied the accounting system of SMEs in the Kumasi metropolis of Ghana. The study was based on primary data collected through structured questionnaires from a sample of 2IO SMEs. The study found that majority of SMEs fail to keep proper accounting records as they feel that it is not necessary; it exposes their financial position; it is time consuming; and expensive. This study reaches the same conclusion with the study of Yousef (2013) "that the level of awareness among SMEs on the importance of proper accounting record keeping is still very low."

Ohachosim et al. (2012) carried out the study of "Financial Challenges of Small and Medium-Sized Enterprises (SMEs) In Nigeria: The Relevance of Accounting Information” from a survey of 348 SMEs in Anambra State. Structured questionnaire were used in data collection. Analysis was by means of ordinary least square (OLS). They found out that poor accounting system is what characterizes most SMEs of Nigeria.

Maseko \& Manyani (20I I) investigate about accounting practices of SMEs in Zimbabwe using Bindura as a case study. Data were gotten from a survey of I00 SMEs through structured questionnaires. The findings revealed that generality SMEs don't keep records because of lack of accounting knowledge. They recommended that the national authorities should develop guidelines of accounting for SMEs and undertake programes for train entrepreneurs of SMEs in accounting. SMEs will contribute, in no small measure, to their performance. In their recommendation, they advised SMEs to consult accountants regularly so that they can be able to maintain high and generally accepted accounting practices.

Tuanmat \& Smith (20II) show that the level of changes of management accounting practices increased during the period of 2003 to 2007 . These changes mostly happened due to the introduction of new practices, replacement of existing practices and modification of the way existing practices were used. Further it found out that there is no any significant difference in management accounting practices among foreign companies and local companies, or between SMEs and large enterprises.

Tzempelikos \& Gounaris (2015) ascertain few key account management practices at the strategic, organizational, and tactical levels of management and offer support for greatest hypothesized relationships, presenting that the recognized practices positively influence performance and dyadic results through the mediation coming from the variables examined. The study extends to understanding of the factors underlying effective Key account management practices based on theoretical perspective.

Many researchers conducted the studies about SMEs with different study problems such as; management issues, accounting issues and financial issues and challenges, reasons of small business failures. Few researchers examined about the contribution of record keeping practices to business performance of SMEs. They have pointed out that, some SMEs produce accounting records based on computerized accounting packages, relying on accountants but often they left the complexity of information, accounting records hinder application of appropriate measures in evaluating business success. Therefore this study attempts to fill this gap.

\section{Methodology}

The methodology is the effective way to achieve the purpose of the study, develop the conceptual framework and explains independent and dependent variables used and operationalization of concepts and variables. Furthermore it discusses the technique adopted for sample selection and data extraction.

Determining the population of SMEs in Sri Lanka is indeterminate. Thus there is no unified database available representing wide range of areas that SMEs are operating like manufacturing, agriculture, mining, construction, service etc. There are I44 SMEs which are registered in Sri Lanka Chamber of Small and medium industries. The primary data were collected from 75 SMEs which were selected by using random sampling technique. I50 questionnaires were issued. A pilot test was performed.

Primary data was obtained from the selected SMEs through structured questionnaires. The questionnaire consists of two sections: Section A and Section B. Section A consists of the questions related to personal information of respondents for the research and section $B$ evaluate the degree of the agreement with the impacts of accounting practices on organizational performance. The respondents were requested to indicate the extent of their agreement with a series of questions on a five-point Likert scale. The collected data was analyzed by using Statistical software for social science (SPSS 2I). 


\section{Conceptualization}

According to literature and problem statement, a conceptual model constructs the research framework. This model represents the relationship between accounting practices and organizational performance.

\begin{tabular}{|l|}
\hline \multicolumn{1}{|c|}{ Accounting Practices } \\
\hline Record keeping \\
- $\quad$ Proper accounting records \\
- $\quad$ Preparation of accounting records \\
- Accounting records procedures \\
Budgeting practices \\
- Budget planning \\
- Budget Information System \\
- Budget Skills Competency \\
Payroll Accounting \\
- $\quad$ Timely payroll accounting \\
- Accurate payroll accounting \\
- $\quad$ Accessible payroll records \\
\hline
\end{tabular}

\begin{tabular}{|ll|}
\multicolumn{1}{c|}{ Organizational Performance } \\
\hline$-\quad$ Organizational Goal achievement \\
- Organizational Effectiveness \\
- Organizational Efficiency records
\end{tabular}

Source: Developed by researcher

Figure I. Conceptual framework

\section{Data Analysis and Discussion}

The data collated through the survey are presented and analyzed for achieving the objective. The study focused entirely on SMEs sector mainly consists of seventy five manufacturing, trading and beverage food and tobacco enterprises. In this study descriptive statistics describe the business characteristics of SMEs and adoptability of accounting practices to develop a general view about the sample of the study.

In pilot testing, validity and reliability were conducted to measure that questionnaires are valid and reliable to be used in this research. According to Hair et al. (1998) validity is "extent to which a measure or set of measures correctly represents the concept of study - the degree to which it is free from any systematic or nonrandom error. Validity is concerned with how well the concept is defined by the measure(s)." Validity in this pilot testing is determined. The result is valid and questions for the entire item are valid and can be used in this study.

According to Hair et al. (1998) reliability is "extent to which a variable or set of variables is consistent in what it is intended to measure." The questionnaire on this study evaluated the reliability by using SPSS software with Cronbach's alpha method. The result will be stated as reliable if the value of Cronbach's alpha value is greater than 0.60. Thus the internal consistency of different accounting practices and organizational performance of this study were verified through Cronbach alpha coefficient.

Table I. Testing the Reliability

\begin{tabular}{|c|c|c|c|}
\hline \multicolumn{2}{|c|}{ Variables } & \multirow{2}{*}{$\frac{\text { Number of items }}{6}$} & \multirow{2}{*}{$\frac{\text { Cronbach's Alpha }}{0.603}$} \\
\hline Record keeping & Proper accounting records & & \\
\hline & Preparation of accounting records & 2 & $0.70 \mathrm{I}$ \\
\hline & Accounting records procedures & 2 & 0.688 \\
\hline \multirow[t]{3}{*}{ Budgeting practices } & Budget planning & 3 & 0.731 \\
\hline & Budget Skills Competency & 5 & 0.725 \\
\hline & Budget Information System & 3 & 0.725 \\
\hline \multirow[t]{3}{*}{ Payroll Accounting } & Timely payroll accounting & 2 & 0.724 \\
\hline & Accurate payroll accounting & 6 & 0.732 \\
\hline & Accessible payroll records & 4 & 0.654 \\
\hline \multicolumn{2}{|c|}{ Organizational performance } & 6 & 0.653 \\
\hline
\end{tabular}

The results represent that the Cronbach's alpha coefficient for each accounting practice exceeds the generally accepted standard of 0.6. All selected accounting practices hold significant reliability test values. Therefore, the data gathered from selected accounting practices of SMEs through questionnaires were considered as reliable. 


\section{I Demographic and Business Characteristics}

The survey of accounting system and organizational performance includes the male-female distinction, education background, size of the business, legal form and number of years in operations of the current business. These features support to recognize the nature of the SMEs in Sri Lankan context with reference to the selected sample of the study. Table 2 represents summary of descriptive statistics pertaining to different demographic and business characteristics of the selected SMEs.

Table 2. Demographic and Business characteristics of the selected sample of SMEs

\begin{tabular}{|c|c|c|}
\hline Demographic Characteristics & Frequency & Percentage \\
\hline \multicolumn{3}{|l|}{ Gender: } \\
\hline Male & 72 & $96 \%$ \\
\hline Female & 03 & $4 \%$ \\
\hline \multicolumn{3}{|l|}{ Position of the Business: } \\
\hline Owner is separate from the manager & 54 & $72 \%$ \\
\hline Both owner and manager is one individual & $2 \mathrm{I}$ & $28 \%$ \\
\hline \multicolumn{3}{|l|}{ Number of years in operations of the current business: } \\
\hline $\mathrm{Up}_{\mathrm{p}}$ to 05 & $2 \mathrm{I}$ & $28 \%$ \\
\hline 05 to 10 & $2 \mathrm{I}$ & $28 \%$ \\
\hline Over I0 & 33 & $44 \%$ \\
\hline \multicolumn{3}{|l|}{ Education: } \\
\hline School level & 52 & $69.33 \%$ \\
\hline Graduate level & I5 & $20 \%$ \\
\hline Professional level & 08 & $10.64 \%$ \\
\hline \multicolumn{3}{|l|}{ Size of the business: } \\
\hline Small & 50 & $66.66 \%$ \\
\hline Medium & 25 & $33.34 \%$ \\
\hline \multicolumn{3}{|l|}{ Legal Form: } \\
\hline Sole-proprietorship & 48 & $64 \%$ \\
\hline Limited Company & 27 & $36 \%$ \\
\hline
\end{tabular}

With regard to the male-female distinction, majority of the business owners are male and it represented $96 \%$ of the sample, thus showing male dominance in the ownership of SMEs. With respect to the management of entities it was noted that around $28 \%$ of businesses are managed by the owners whereas the rest of the organizations are managed by a manager who is not an owner of the business.

The majority of SMEs have been conducting its operations more than five years $(72 \%)$. Further qualifications of owners revealed that more than $69 \%$ of the SME owners possess School level education. However, the level of professional achievements and qualifications of owners were at a low level. The classification between small and medium businesses revealed that more than $33 \%$ entities satisfied the criteria to be considered them as medium size businesses. From the legal form of SMEs' perspective, it was revealed that more than $64 \%$ of SMEs are Sole-proprietorship.

\subsection{Multicollinearity}

Multicollinearity represents that two or more independent variables are highly correlated with each other. Multicollinearity refers to the successive inclusion of additional variables that lift the collinearity of the full set of explanatory variables to a 'harmful' level (Lauridsen \& Mur, 2006).

Table 3. Multicollinearity

\begin{tabular}{|c|c|c|}
\hline \multirow[t]{2}{*}{ Model } & \multicolumn{2}{|c|}{ Collinearity Statistics } \\
\hline & Tolerance & VIF \\
\hline Record keeping & .869 & I.I50 \\
\hline Budgeting practices & .925 & 1.000 \\
\hline Payroll Accounting & .869 & I.I5I \\
\hline
\end{tabular}

Variance inflation factor (VIF) is a technique used to identify the multicollinearity using SPSS and, if the VIF is greater than I0, which is a clear case of multicollinearity (Hair et al., I995). In this study multicollinearity problem don't arise among the variables as all variance inflation factors are less than IO. 


\subsection{Correlation Analysis}

Correlation is a statistical technique for examining the relationship between two variables. It establishes an invaluable initial analysis and a building a basis for further analysis. In accordance with the correlation matrix represented in table 04, Record Keeping and Payroll Accounting have a significant relationship with organizational performance at $5 \%$ levels $\left(\mathrm{r}=.3 \mathrm{I} 7^{\text {th }}, \mathrm{P}<\right.$ 0.05 and $\mathrm{r}=.225, \mathrm{P}<0.05)$ ) respectively. There is a significant relationship between budgeting practices and organizational performance at $10 \%$ levels $(\mathrm{r}=.2 \mathrm{I} 7, \mathrm{P}<0.05)$.

Table 4. Correlations Matrix for accounting practices and organizational performance

\begin{tabular}{|c|c|c|c|c|c|}
\hline & & (I) & (2) & (3) & (4) \\
\hline \multirow[t]{3}{*}{ (I) Record Keeping } & Pearson Correlation & \multirow{2}{*}{\multicolumn{4}{|c|}{$\mathrm{I}$}} \\
\hline & & & & & \\
\hline & Sig. (2-tailed) & & & & \\
\hline \multicolumn{6}{|c|}{ (2) Budgeting practices } \\
\hline & Pearson Correlation & & & & \\
\hline & & .003 & $\mathrm{I}$ & & \\
\hline & Sig. (2-tailed) & .982 & & & \\
\hline \multicolumn{6}{|l|}{ (3) Payroll Accounting } \\
\hline & Pearson Correlation & & & & \\
\hline & & 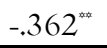 & -.022 & I & \\
\hline & Sig. (2-tailed) & .001 & .854 & & \\
\hline \multirow[t]{3}{*}{$\begin{array}{l}\text { (4) Organizational } \\
\text { performance }\end{array}$} & Pearson Correlation & & & & \\
\hline & & $.317^{\text {wa }}$ & .217 & .225 & I \\
\hline & Sig. (2-tailed) & .006 & $.06 \mathrm{I}$ & .0500 & \\
\hline
\end{tabular}

\subsection{Multiple Regression Analysis}

Table 5 represents the results of multiple regression analysis to study the impact of accounting practices and organizational performance of SMEs in Sri Lanka.

Table 5. Regression coefficients for accounting practices and organizational performance.

\begin{tabular}{|c|c|c|c|c|c|}
\hline Model & & B & Std. Error & $\mathrm{t}$ & Sig \\
\hline I (Constant) & 5.447 & & $.7 \mathrm{I} 2$ & 7.653 & .000 \\
\hline Record Keeping & .119 & & $.05 \mathrm{I}$ & 2.316 & .023 \\
\hline Budgeting practices & .249 & & .122 & 2.035 & .046 \\
\hline Payroll Accounting & .087 & & .077 & I.I40 & .258 \\
\hline Adjusted $\mathrm{R}^{2}-0.368$ & & & lue -4.623 & $=0.05)$ & \\
\hline
\end{tabular}

As shown in table 5 among three accounting practices only record keeping and budgeting practices have a significant influence on organizational performance at 0.05 levels $(\beta=.119, \mathrm{P}<0.05$ and $\beta=.249, \mathrm{P}<0.05)$ respectively. Further payroll accounting is not significant and influencing on organizational performance $(\beta=.087, P<0.05)$. Therefore it can be concluded that only record keeping and budgeting practices have a substantial positive influence on organizational performance. This finding is collaborated with previous study of Onaolapo \& Adegbite (2014).

The adjusted $R^{2}$ Value for accounting practices and organizational performance is 0.368 which represents that $36.8 \%$ percent of the variability in organizational performance is determined by accounting practices such as record keeping, budgeting practices and payroll accounting and the remaining $63.2 \%$ of the variance is not shown in this model. As $F$ value is $4.623(\mathrm{P}=0.05)$ in this analysis the regression model is more applicable for this study.

\section{Conclusion and Recommendation}

This study was designed for exploring the extent of use of accounting practices among SMEs Sri Lanka and to find if there is any significant influence on organizational performance. This study mainly focus on Small and medium enterprises in Sri Lanka and seventy five small and medium enterprises have been selected as sample while Pearson's correlation and multiple regression analysis have been performed to investigate the influence of accounting practices on organizational performance. The findings of this study reveals that among the accounting practices, only record keeping and budgeting practices have significant positive influence on organizational performance of Small and medium enterprises in Sri Lanka. 
It can be recommended that academic institutions and other bodies which are responsible for SMEs should organize training programmes for those operators who do not have the technical knowhow in the field of accounting to come to grips with it and also provide some SME-specific accounting guidelines and template forms for capturing accounting practices for the operators to use.

\section{References}

Aremu, M. A., \& Adeyemi, S. L. (20II). Small and medium scale enterprises as a survival strategy for employment generation in Nigeria. Joumal of sustainable development, 4(I), 200.

Amaoko, G. B. (2013). Accounting practices of SMEs: A case study of Kumasi metropolis in Ghana. International Journal of Business and Management, 8(24), 73-83.

Abeygunasekera, A.W. J. C., \& Fonseka, A. T. (2012). Non-compliance with standard accounting practices by small and medium scale enterprises in Sri Lanka. Postgraduate Institute of Management, University of Sri Jayawardenepura, Sri Lanka.

Cooley, P., \& Edwards, C. (1983). Financial objectives of small firms. American Joumal of Small Business, 8(I), 28-3I.

European Commission. Directorate-General for Economic.(2008).EMU@IO: successes and challenges after IO years of Economic and Monetary Union (No. 2). European Communities.

Hair, J. F., Black, W. C., Babin, B. J., Anderson, R. E., \&Tatham, R. L. (1998). Multivariate data analysis, 5(3), $207-219$. Upper Saddle River, NJ: Prentice hall.

Karunananda, A., \& Jayamaha, A. (20II). Financial practices and performance of small and medium-size enterprises in Sri Lanka. Proceedings of International Conference on Business \& Information. Available from: Digital Repository.kln.ac.lk.

Lauridsen, J., \& Mur, J. (2006). Multicollinearity in cross-sectional regressions. Journal of Geographical Systems, $8(4), 317-333$.

Maseko, N., \& Manyani,O. (20II). Accounting Practices of SMEs in Zimbambwe. Journal of Accounting and Taxation, 3(8), I7I - I8I.

Ohachosim, C. I., Onwuchekwa, F. C., \& Ifeanyi, T. T. (2012). Financial challenges of Small and Medium-Sized Enterprises (SMEs) in Nigeria. The Relevance of Accounting Information. Review of Public Administration and Management, I(2), 77-99.

Onaolapo, A., \& Adegbite, I. (2014). The Analysis of the Impact of Accounting Records Keeping on the Performance of Small Scale Enterprises. International Journal of Academic Research in Business and Social Sciences, 4.http://dx.doi.org.I0.6007/IJARBSS/V4-iI/506.

Onaolapo, A. A., Fasina, H. T., Opoola, N. A., \&Olatunji, A. (20II). Basic Accounting One. Ogbomosho: Johnny Printing Works.

Tuan ZainunTuanmat and Malcolm Smith (201I). Changes in management accounting practices in Malaysia. Asian Review of Accounting, I9(3), 22I-242.

Tzempelikos, N., \& Gounaris, S. (2015). Linking key account management practices to performance outcomes. Industrial Marketing Management, 45.22-34.

Yousef, B. (2013). The use of accounting information by Small and medium enterprises in south district of Jordan (An empirical study). Research journal of finance and accounting, 4(6), I69-I75.

\section{Copyrights}

Copyright for this article is retained by the author(s), with first publication rights granted to the journal. This is an openaccess article distributed under the terms and conditions of the Creative Commons Attribution license (http://creativecommons.org/licenses/by/4.0/). 